\title{
Carbon Nanotube Layer for Reduction of Fiber Print-Through in Carbon Fiber Composites
}

\author{
Joana F. Guedes $\left(\mathbb{D},{ }^{1}\right.$ Marta S. S. Martins, ${ }^{1}$ Ramiro Martins, ${ }^{2}$ and Nuno Rocha ${ }^{1}$ \\ ${ }^{1}$ INEGI - Institute of Science and Innovation in Mechanical and Industrial Engineering, Campus da FEUP, \\ Rua Dr. Roberto Frias 400, 4200-465 Porto, Portugal \\ ${ }^{2}$ Instituto Superior de Engenharia do Porto, Rua Dr. António Bernardino de Almeida 431, 4200-072 Porto, Portugal \\ Correspondence should be addressed to Joana F. Guedes; jguedes@inegi.up.pt
}

Received 29 March 2018; Accepted 14 May 2019; Published 12 June 2019

Academic Editor: Avraam I. Isayev

Copyright (C) 2019 Joana F. Guedes et al. This is an open access article distributed under the Creative Commons Attribution License, which permits unrestricted use, distribution, and reproduction in any medium, provided the original work is properly cited.

\begin{abstract}
Fiber print-through effect is a limitation to the use of carbon fiber-reinforced composites in space applications, namely, mirror telescopes. Replica method is used for the production of lightweight telescope mirrors. However, this method requires a polished mandrel, increasing considerably the final cost. In this work, we report a cheaper and simpler alternative production method, which consists in the addition of a carbon nanotube filled epoxy resin layer on the surface of carbon reinforced composites, in order to reduce fiber print-through of the materials. The influence of different carbon nanotube functionalizations, concentrations, and dispersion levels are also assessed. The surface properties are evaluated by interferometry (roughness and waviness) and scanning electron microscopy (morphology). The results show that the waviness, roughness, and consequently fiber print-though are considerably reduced with the addition of a thin layer of nonfunctionalized carbon nanotubes.
\end{abstract}

\section{Introduction}

A telescope is composed of several components, with the primary mirror being the most important, since its function is to collect and focus the light [1-3]. In a telescope, a typical mirror has a mass of approximately $30 \mathrm{~kg}$, increasing for $150 \mathrm{~kg}$ when the support structure is added [3]. The replacement of traditional materials (silicon carbide, metals, and ceramics) by lightweight materials is mandatory for the reduction of the launching costs, turning space missions faster and cheaper [1, 3-7]. Carbon fiber-reinforced plastics (CFRP) are promising candidates for replacing heavy traditional materials, as they reduce the final weight of the entire mirror and at the same time have low coefficient of thermal expansion (CTE), high stiffness, and thermal stability $[1,7,8]$. The fiber print-through effect is one of the main problems about using the CFRP in optical mirror, which contributes to the reduction of mirror smoothness and accuracy [1]. Fiber print-through occurs when the ribs or fibers overlap each other in the mirror surface, creating residual stresses during the solidification process $[1,2,4]$.
In order to obtain a better surface quality, the CFRP optical mirror is manufactured using the replica method, where a composite material is positioned on a polished mandrel or mold with superior surface quality (usually glass) and the required shape $[1,3,4]$. The same mold can be used several times to produce a large number of samples with high precision and uniformity, but at the same time it is a process very dependent on the precision of the mandrel, requiring specific tools for each shape, which makes it expensive $[1,3]$.

To make the process simpler, faster, and cheaper, it is necessary to find an alternative that is independent of the use of molds. An alternative reported by some authors is the application of a resin layer through the CFRP, reducing fiber print-through and consequently improving the surface roughness and accuracy. Massarello et al. [9] studied the reduction of fiber print-through effect by addition of a resin layer and magnetic fiber migration (MFM). Here, the authors concluded that both mitigate fiber print-through, but the lack of uniformity of magnetic field density and the relationship between the print-through amplitude and the thickness of the resin layer are imperceptible. Arao et al. [2] applied a 
TABLE 1: Types of carbon nanotube masterbatches used.

\begin{tabular}{lcc}
\hline CNT designation & \multicolumn{2}{c}{ Functionalization Type } \\
\hline AP & None & As produced \\
A & Acid oxidized & Chemically treated \\
T & Thermally oxidized & Thermally treated \\
TD & Thermally oxidized & With dispersing agent \\
\hline
\end{tabular}

resin layer in CFRP surface and observed that, for uncoated samples, RMS (root mean square) was $120 \mathrm{~nm}$, being reduced for 10-20 nm with resin coating application. Kamiya et al. [10] applied the same method and obtained a reduction of RMS from $510 \mathrm{~nm}$ to $5.1 \mathrm{~nm}$.

Carbon nanotubes (CNT) can be added as a means to provide multifunctionality to CFRP materials for aerospace structures, because of their unique physical, thermal, and optical properties [11-14]. When transferred efficiently to the composite, they are expected to provide mechanical improvements (strength, stiffness, interlaminar shear strength) and enhance the thermal and electrical properties $[15,16]$. Chen and Rabin [17] showed that it is possible to produce epoxy/CNT composites with surface optical quality to be used as mirrors using the replica method. Kia [18] has patented a method for reducing the fiber print-through in composites reinforced with long fibers with the addition of CNT. A polymeric prepreg layer reinforced with vertically oriented nanotubes was applied transversally to the thickness of the CFRP. However, for optical mirror application, the vertically aligned CNT are near to a black body absorber, which means that the CNT do not reflect the incident light [19-22].

This work aimed to reduce the surface roughness of CFRP composites and, consequently, to reduce the fiber printthrough effect, based on the application of an upper epoxy layer doped with CNT. Contrary to commonly reported replica technique, in this work, high precision molds were not used to obtain a high quality surface. Furthermore, the nanotubes were not aligned, as already reported by other authors. CFRP materials intended to be used for optical mirrors were manufactured with a rich CNT epoxy layer, where the nanotubes were randomly dispersed in the matrix. The effects of CNT concentration, dispersion, and functionalization were also assessed.

\section{Experimental}

2.1. Materials. The resin system used was supplied by Huntsman and it is composed of LY556 resin combined with an anhydride curing agent (HY906) and an imidazole accelerator (DY070).

Fiber-reinforced composites were obtained by using HexPly ${ }^{\circledR} 8552$ preimpregnated sheets supplied by Hexcel, reinforced with T700 unidirectional carbon fibers.

Carbon nanotubes were supplied by Future Carbon $\mathrm{GmbH}$ in the form of masterbatch. Four different types of masterbatches were used: CNT as produced; CNT acid oxidized; CNT thermally treated; and CNT thermally oxidized with dispersing agent (Table 1).
2.2. Sample Preparation. The CNT dispersion was diluted from 2 wt.\% concentrated masterbatch to $1 \mathrm{wt} . \%$ by adding the proper resin amount. The mixture was mechanically stirred at $1500 \mathrm{rpm}$ during 30 minutes at room temperature. In order to evaluate the effect of CNT dispersion, three samples (containing "as produced" nanotubes, since these were the ones providing better results) were further dispersed in a three-roll miller machine (EXAKT 80E). The dispersion program was defined in five steps with decrease of velocity for removing/reducing bubbles in the mixture, and reduction of gap distance to increase the dispersion level [23].

The curing agent and accelerator were then added and mixed using a mechanical stirring at $1000 \mathrm{rpm}$ for 30 minutes with temperature (until $80^{\circ} \mathrm{C}$ ) in order to reduce the mixture viscosity and facilitate the deposition in the CFRP.

Seven layers of prepregs with dimensions of $100 \mathrm{~mm}^{2}$ were stacked with a unidirectional lay-up. The resin layer was added as surface coating before the materials were cured. To evaluate the influence of resin-CNT layer thickness, one sample was prepared with four layers of CFRP and the equivalent of four layers of resin.

Resin curing was performed using the following conditions: 60 minutes at $110^{\circ} \mathrm{C}$ plus 120 minutes at $180^{\circ} \mathrm{C}$ in a hot press ( 2 bar) plus 60 minutes at $220^{\circ} \mathrm{C}$ in an electrical oven. The final thickness of the composite was of approximately $1 \mathrm{~mm}$. Two reference samples, one without any top layer and one containing a resin system without CNT as top layer, were also prepared for comparison purposes. Table 2 provides a list of all manufactured composites.

\subsection{Samples Characterization}

2.3.1. Visual Inspection. After cure cycle and demolding, the samples were visually inspected with the naked eye. Warpage effect, uniformity of top layer, and brightness of samples were evaluated.

2.3.2. Surface Roughness and Waviness Analysis. The roughness was evaluated using a white light interferometer (Bruker NPFLEX). The measuring area was of $2 \mathrm{~mm} \times 2 \mathrm{~mm}\left(4 \mathrm{~mm}^{2}\right)$. The evaluation of the roughness parameters was performed in two orthogonal directions: in the fiber direction and perpendicular to the fiber direction. A $250 \mu \mathrm{m}$ Gaussian regression filter was applied.

Roughness is the most used parameter for the surface evaluation; however, in this study, waviness was also studied. Roughness and waviness are two similar concepts. While roughness is evaluated in relation to small spaced deviations from an ideal shape, waviness is evaluated in relation to large spaced irregularities [24]. Figure 1 shows the representation of these parameters. 
TABLE 2: Composites prepared and their characteristics.

\begin{tabular}{|c|c|c|c|c|}
\hline Sample designation & Top layer added? & CNT type and loading & \# of CFRP layers & CNT dispersion method \\
\hline IM7 & No & --- & --- & --- \\
\hline IM7/LY556 & Resin & --- & 7 & --- \\
\hline $\mathrm{IM} 7 / 1 \mathrm{~T}$ & Resin + CNTs & $\begin{array}{c}1 \mathrm{wt} . \% \text { thermally } \\
\text { oxidized }\end{array}$ & 7 & Mechanical Stirrer \\
\hline IM7/1A & Resin + CNTs & 1 wt.\% acid oxidized & 7 & Mechanical Stirrer \\
\hline IM7/1TD & Resin + CNTs & $\begin{array}{c}1 \text { wt.\% thermally } \\
\text { oxidized with dispersing } \\
\text { agent }\end{array}$ & 7 & Mechanical Stirrer \\
\hline IM7/1AP & Resin + CNTs & $1 \mathrm{wt} . \%$ as produced & 7 & Mechanical Stirrer \\
\hline $\mathrm{IM} 7 / 1 \mathrm{AP}(4)-3 \mathrm{R}$ & Resin + CNTs & $1 \mathrm{wt} . \%$ as produced & 4 & $\begin{array}{l}\text { Mechanical Stirrer } \\
\text { +Three-roll miller } \\
\text { machine }\end{array}$ \\
\hline IM7/1AP-3R & Resin + CNTs & $1 \mathrm{wt} . \%$ as produced & 7 & $\begin{array}{c}\text { Mechanical Stirrer }+ \\
\text { Three-roll miller } \\
\text { machine }\end{array}$ \\
\hline IM7/2AP-3R & Resin + CNTs & $2 \mathrm{wt} . \%$ as produced & 7 & $\begin{array}{c}\text { Mechanical Stirrer } \\
\text { +Three-roll miller } \\
\text { machine }\end{array}$ \\
\hline
\end{tabular}

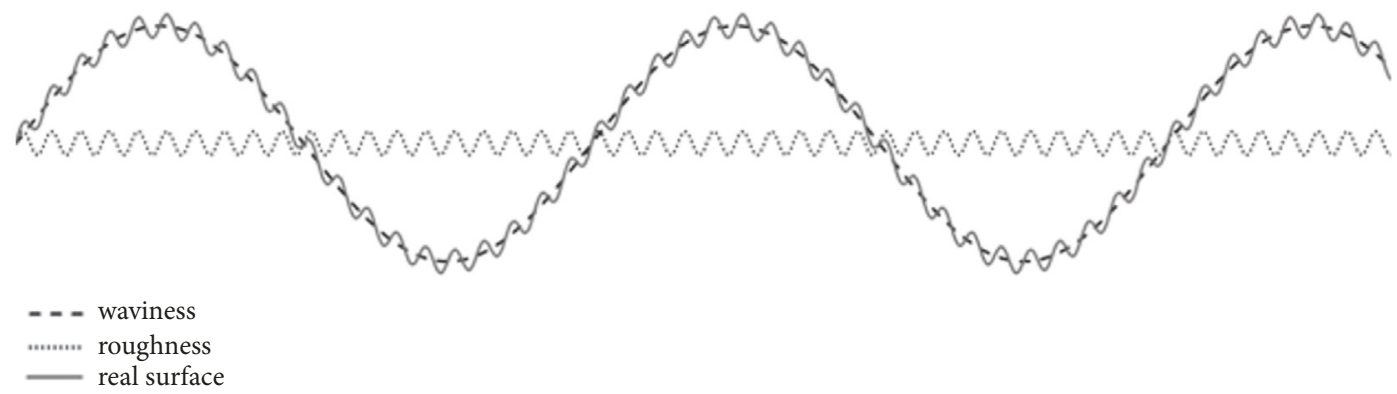

FIGURE 1: Representation of surface defects.

The most usual and relevant parameter to quantify surface roughness is $\mathrm{Rq}$ (also called RMS, root mean square), which represents the deviation of the distribution of surface heights in relation to an ideal surface [25]. $\mathrm{R}_{\mathrm{zDIN}}$ (average maximum height of the roughness profile) and $\mathrm{R}_{\max }$ (maximum height of the roughness profile) are also important parameters for the evaluation of surface accuracy, since smaller values in these parameters indicate surfaces with lower maximum heights/defects. $\mathrm{R}_{\mathrm{zDIN}}$ is obtained by dividing the obtained profile into 5 parts and then measuring the difference between the highest peak and the lower valley of each part, while $\mathrm{R}_{\max }$ is the maximum value obtained from the 5 previous peak-to-valley differences [25]. Waviness interpretation is the same as that for roughness, but applied to large space irregularities [25]. Wq (root mean square waviness), $\mathrm{W}_{\mathrm{zDIN}}$ (average maximum height of the waviness profile), and $\mathrm{W}_{\max }$ (maximum height of the waviness profile) were the waviness parameters studied.

2.3.3. Microstructure Analysis. The surface of the composites and the cohesion between the layers were examined by scanning electronic microscopy (SEM) using a FEI Quanta 400 FEG ESEM microscope. The samples were fractured in liquid nitrogen and covered with a layer of gold/palladium to increase the surface conductivity and, consequently, the contrast of the obtained images. Cross-sectional images were obtained in secondary electrons (SE) mode, while the surface images were obtained in backscattering electron (BSE) mode to obtain images with higher contrast.

\section{Results and Discussion}

3.1. Visual Inspection. Figure 2 presents some representative images of the surface of the obtained composite materials.

In the visual analysis of the samples, the brightness, the uniformity of top layer, and the warpage were evaluated. IM7 presents a bright surface with no warpage effect. When a resin layer is added (IM7/LY556), it is observed that the surface was bright and uniform, but exhibits a slight warpage. When different CNT are added as top layer, the surface of the materials is brighter; however, some small dry areas are observed. Samples prepared with "as produced" nanotubes show brighter surface with fewer dry areas. It is also visualized that the addition of CNT increases the warpage effect. 


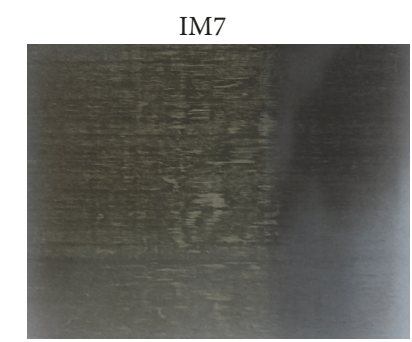

IM7/1A

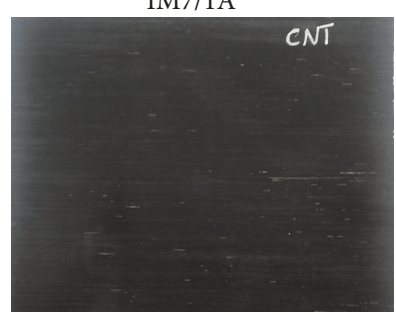

IM7/1AP-3R
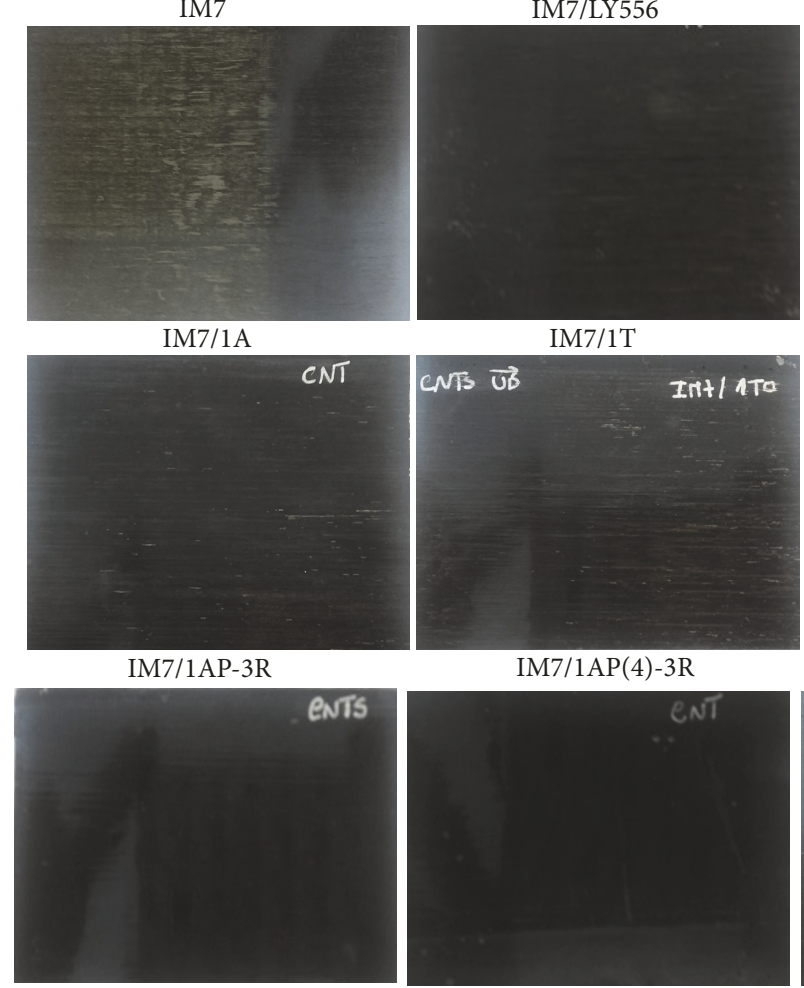

IM7/1T

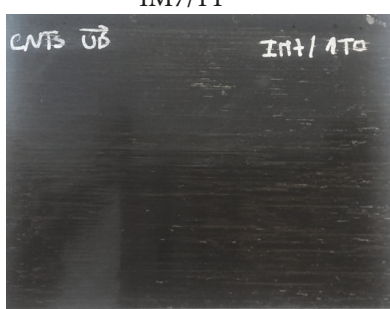

IM7/1AP(4)-3R

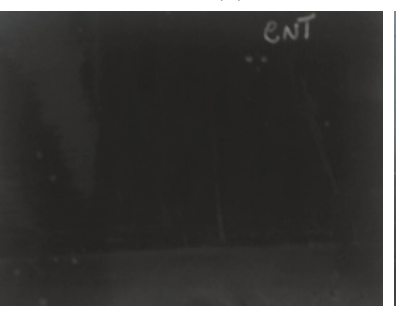

FIGURE 2: Visual inspection of all samples prepared.
IM7/1AP

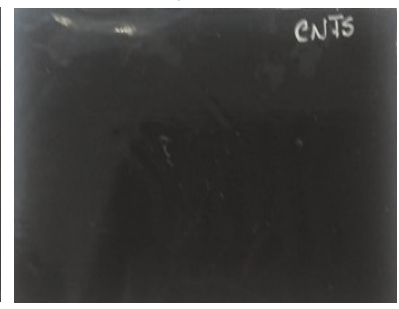

IM7/1TD

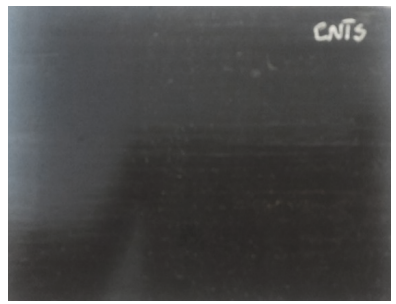

IM7/2AP-3R

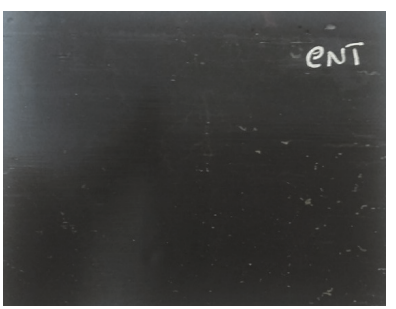

3.2. Interferometry Surface Analysis. Roughness and waviness were evaluated for all manufactured composites by interferometry. The 3D surface images obtained are shown in Figure 3.

By analyzing Figure 3, it is possible to make a first analysis of the roughness and waviness of the composites (same vertical scale for all images, ranging between $-5 \mu \mathrm{m}$ and $5 \mu \mathrm{m}$ ). When the surface of the material is more uniform (less roughness), the green color is predominant in 3D surface images. When red and blue colors dominate the image, the surface of the material presents large deviations from an ideal surface and, therefore, a rougher surface.

The IM7 sample, where no additional layer is added, shows a very rough surface, with the predominance of red and blue colors. The ribs of fiber can be clearly identified, highlighting the print-through. When a resin layer (with or without CNT) is added to the CFRP, the fiber direction becomes less evident for all samples, suggesting a decrease of fiber print-through by a reduction of surface roughness. In the same figure, it is observed that sample prepared with resin without CNT (IM7/LY556) presents some peaks and valleys represented by red and blue colors, respectively. When the functionalized CNT are added to LY556, the green color is predominant, indicating that the surface is less rough; however, some peaks and valleys are still visualized. The predominance of green color in the samples prepared with 1 wt.\% of "as produced" CNT (IM7/1AP, IM7/1AP-3R and IM7/1AP(4)-3R) suggests a less rough surface, the nearest to an ideal surface. As expected, the sample with the thicker
CNT layer (IM7/1AP(4)-3R) presents a more regular surface, with a predominance of green color, suggesting that it is the best option for reducing the surface roughness of the materials.

Waviness is not identified by color differences, but by the presence of visual undulations on the surface, being less evident and more difficult to identify than roughness. The sample without any resin top layer (IM7) presents a wavy surface. In the sample with resin without CNT at the top (IM7/LY556) and samples produced with functionalized CNT (IM7/1T, IM7/1A and IM7/1TD), some undulations and surface peaks are observed. For samples prepared with "as produced", with no functionalized CNT (IM7/1AP, IM7/1AP3R, IM7/1AP (4) -3R, and IM7/2AP-3R), surface presents some but less pronounced undulations.

The last results are only indicative of the surface quality and it is necessary to quantify the improvement of surface roughness. For this, to quantify the roughness and waviness of composites, 2D parameters are evaluated and compared. Table 3 shows the roughness parameters obtained, as well as the percentage reduction of the roughness parameters in relation to the reference sample (IM7).

The IM7 sample has a RMS of $2528 \mathrm{~nm}$, decreasing considerably when an additional resin layer is added (65$96 \%$ ). The addition of a pure resin layer (sample IM7/LY556) decreases the RMS value from $2528 \mathrm{~nm}$ to $552 \mathrm{~nm}$, representing a $78 \%$ reduction. The samples prepared with functionalized CNT have different values of RMS. When the acid oxidized CNT are applied to the top layer, the value 
TABLE 3: 2D parameters of roughness measurement of materials prepared ${ }^{\mathrm{a}}$.

\begin{tabular}{|c|c|c|c|c|c|c|c|c|}
\hline \multirow{2}{*}{$\begin{array}{l}\text { Composite } \\
\text { designation }\end{array}$} & \multicolumn{2}{|c|}{$\mathrm{R}_{\mathrm{q}}$} & \multicolumn{2}{|c|}{$\mathrm{R}_{\mathrm{zDIN}}$} & \multicolumn{2}{|c|}{$\mathrm{R}_{\max }$} & \multicolumn{2}{|c|}{$\mathrm{R}_{\max }-\mathrm{R}_{\mathrm{zDIN}}$} \\
\hline & $\begin{array}{l}\text { Measurement } \\
(\mathrm{nm})\end{array}$ & $\begin{array}{l}\text { Reduction } \\
(\%)\end{array}$ & $\begin{array}{l}\text { Measurement } \\
(\mathrm{nm})\end{array}$ & $\begin{array}{l}\text { Reduction } \\
\text { (\%) }\end{array}$ & $\begin{array}{l}\text { Measurement } \\
(\mathrm{nm})\end{array}$ & $\begin{array}{l}\text { Reduction } \\
(\%)\end{array}$ & $\begin{array}{l}\text { Measurement } \\
(\mathrm{nm})\end{array}$ & $\begin{array}{c}\text { Reduction } \\
(\%)\end{array}$ \\
\hline IM7 & 2528 & -- & 11010 & -- & 15623 & $\mathrm{X}$ & 4613 & $\mathrm{X}$ \\
\hline IM7/LY556 & 552 & 78 & 3815 & 65 & 7283 & 53 & 3468 & $25 \%$ \\
\hline IM7/1T & 875 & 65 & 3119 & 72 & 7018 & 55 & 3899 & $15 \%$ \\
\hline IM7/1A & 307 & 88 & 1537 & 86 & 2739 & 82 & 1202 & $74 \%$ \\
\hline IM7/1TD & 254 & 90 & 1229 & 89 & 1954 & 87 & 725 & $84 \%$ \\
\hline IM7/1AP & 117 & 95 & 816 & 93 & 1401 & 91 & 585 & $87 \%$ \\
\hline $\begin{array}{l}\text { IM7/1AP(4)- } \\
3 \mathrm{R}\end{array}$ & 100 & 96 & 628 & 94 & 959 & 94 & 331 & $93 \%$ \\
\hline IM7/1AP-3R & 122 & 95 & 645 & 94 & 980 & 94 & 335 & $93 \%$ \\
\hline IM7/2AP-3R & 230 & 91 & 1267 & 88 & 1570 & 90 & 302 & $93 \%$ \\
\hline
\end{tabular}

${ }^{a}$ Results present the average of values for both directions studied. The percentage of reduction is relative to IM7 composite (without any additional surface layer).
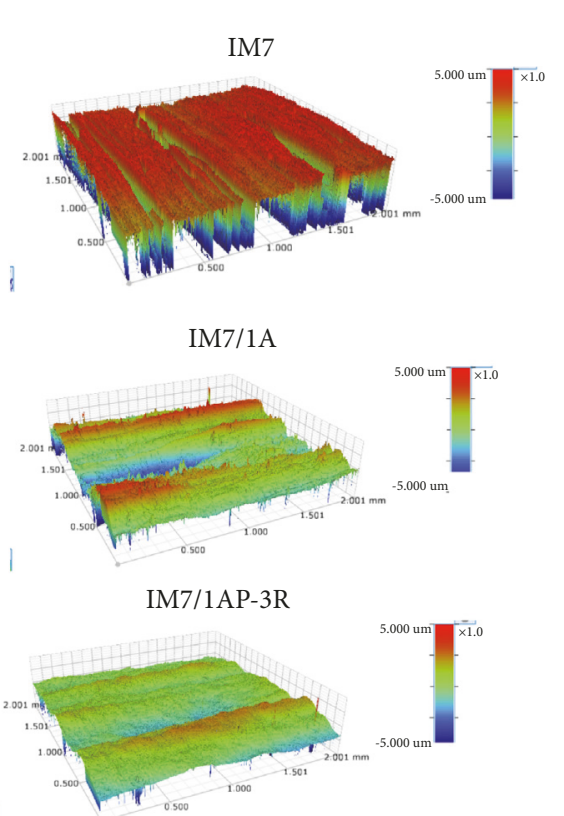
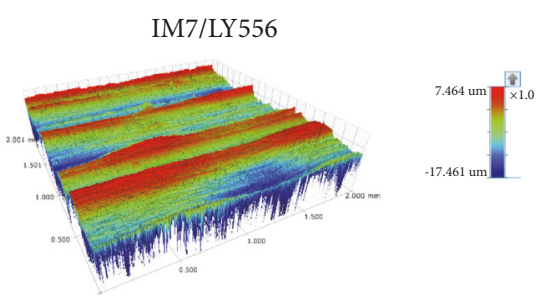

IM7/1T
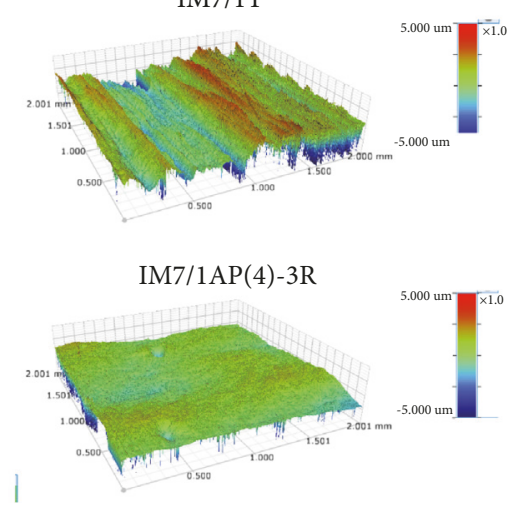

IM7/1AP

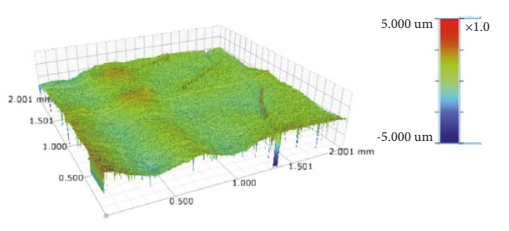

IM7/1TD
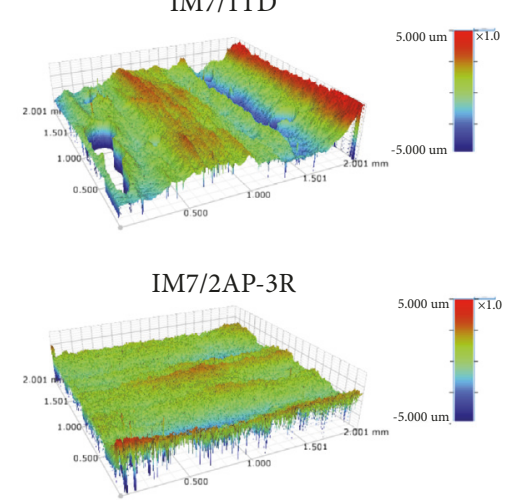

FIGURE 3: 3D surface map images of prepared composites.

decreases by $88 \%$, while thermally oxidized CNT reduce the RMS by $65 \%$, being further reduced by $90 \%$ when the dispersing agent is added. CNT-based composites without any type of surface functionalization (AP) present the lowest RMS values (reduction of 91\%-96\%). These higher RMS reductions can be explained by the probable lower affinity of the nonfunctionalized nanotubes to the resin matrix. The resin layer is therefore composed of carbon nanotubes that do not migrate to the CFRP structure during the curing process, allowing for a more compact and concentrated surface layer. The dispersion of nonfunctionalized nanotubes in a three-roll machine does not have a significant impact on RMS values (IM7/1AP-3R and IM7/2AP-3R).

Depending on the type of functionalization, different results of the influence of the CNT dispersion on RMS are obtained. As mentioned previously, for functionalized CNT (IM7/1TD), it can be concluded that addition of a dispersant agent improved RMS, whereas for nonfunctionalized CNT (IM7/1AP-3R and IM7/2AP-3R) the introduction of a dispersion step does not improve the RMS. For "as produced" CNT, the mechanical dispersion is used. In this method, CNT are typically separated from each other, but the possibility of their fragmentation is high and the dispersion stabilization is poor [26-28]. With the use of a three-roll mill machine, large CNT agglomerates are dispersed in small ones; however, the differences between the roller gap and CNT dispersions make this method less effective for small agglomerates or individual CNT [23]. On the other hand, thermally oxidized CNT are chemically dispersed noncovalently by the addition of a dispersing agent (surfactant). In this type of dispersion, 
structure and electronic performance of CNT are maintained and CNT mixture is stabilized $[28,29]$. These different dispersion methodologies can explain the different RMS results. The mechanical dispersion does not permanently stabilize the CNT and, for this, the CNT tend to agglomerate again easily, which results in a small improvement in surface roughness between similar samples. However, by chemical dispersion, the CNT tend to stabilize for longer, improving surface roughness. For this, it is expected that the addition of a strong dispersant to "as produced" CNT further increases the RMS.

With the increase of CNT concentration to $2 \mathrm{wt} . \%$ surface becomes more rough. This increase may be due to very high viscosity of the sample, making it difficult to create a homogeneous coating. As expected, the better RMS result corresponds to the thicker top layer sample prepared with nonfunctionalized CNT (IM7/1AP(4)-3R) with a 96\% decrease of in RMS compared to IM7. As reported by Arao et al. [2], in composite materials the equilibrium between the composite weight and the CNT thickness is very important, since the increase in the thickness of CNT increases the weight of the composite, which consequently can have a significant impact on its performance. Although the composite with the highest CNT layer thickness (IM7/1AP(4)-3R) presents a greater decrease in roughness, a thin layer of resin-CNT ( $125 \mu \mathrm{m}$ of thickness) is sufficient to significantly decrease the fiber print-thought effect. Sample with the thicker CNT layer (IM7/1AP(4)-3R) presented a RMS of $100 \mathrm{~nm}$, while the same sample with only one layer of CNT (IM7/1AP) presented a RMS value of $177 \mathrm{~nm}$, with this composite being more interesting for the final application.

Kamiya et al. [10] reported that using replica method, the roughness of pitch/cyanate ester composites was reduced by $99 \%(510 \mathrm{~nm}$ to $5.1 \mathrm{~nm})$. In our work, the same range of reduction was obtained only with application of a resin layer and without the utilization of molds.

For $\mathrm{R}_{\mathrm{zDIN}}$, it is observed that the surface without any top resin layer presents an average between upper and lower peaks of five studied parts of $11010 \mathrm{~nm}$. This value is drastically reduced by the addition of resin for $3815 \mathrm{~nm}$ (65\%). The addition of CNT reduces this value even further from $3119 \mathrm{~nm}$ to $628 \mathrm{~nm}$. In the samples with the CNT in top layer, IM7/1T has the highest value of $R_{\mathrm{zDIN}}$, being drastically reduced when a dispersing agent is added to $816 \mathrm{~nm}$, reinforcing that the level of dispersion has a significant impact on the samples with functionalized CNT. CNT samples without functionalizations present again the best results, with $\operatorname{IM} 7 / 1 \mathrm{AP}(4)-3 \mathrm{R}$ being the composite with the lowest value $(628 \mathrm{~nm})$ followed by IM7/1AP-3R $(645 \mathrm{~nm})$. This decrease in $\mathrm{R}_{\mathrm{zDIN}}$ means that the difference between upper and lower peaks in five parts of the profile is smaller, suggesting an increase in surface uniformity.

$\mathrm{R}_{\mathrm{zDIN}}$ and $\mathrm{R}_{\max }$ complement each other. If $\mathrm{R}_{\mathrm{zDIN}}$ and $\mathrm{R}_{\max }$ have similar values, it is suggested that the maximum surface defects are similar and, consequently, the surface is more homogeneous. On the other hand, when $\mathrm{R}_{\mathrm{zDIN}}$ and $\mathrm{R}_{\max }$ have very different values, it is suggested that the surface defects are much higher than the average of the defects and, therefore, the surface is less homogeneous. In Table 3, it can be seen that the $\mathrm{R}_{\max }$ values are always higher than $\mathrm{R}_{\mathrm{zDIN}}$ values; however, some samples have greater homogeneity than others. As expected, IM7 presents the largest difference between $R_{z D I N}$ and $\mathrm{R}_{\max }$ and consequently less homogeneous surface. When a resin top layer is added (IM7/LY556), this difference decreases by $25 \%$, which suggests an improvement in surface homogeneity. The addition of carbon nanotubes has different effects. The addition of thermally oxidized CNT (IM7/1T) increases the difference between the two values (only $15 \%$ reduction over IM7), suggesting a decrease in surface quality. On the other hand, the addition of other functionalized CNT (IM7/1A and IM7/1TD) and nonfunctionalized CNT significantly decreased this difference (74\%-93\%), with the samples prepared with "as produced" CNT presenting lower values (93\% reduction in relation to IM7), suggesting that the surface is more homogeneous.

As for roughness, the waviness parameters are obtained. Table 4 presents the waviness parameters, as well as the reduction percentage in relation to the sample with no additional top layer (IM7).

The interpretation of each waviness parameter is the same for roughness. As expected, the composite without a top resin layer (IM7) has the highest waviness value for all parameters studied. When a coating of LY556 is added, the Wq reduces by $56 \%$. When different types of CNT are added to the LY556, different effects are observed. When thermally and acid oxidized CNT (IM7/1T and IM7/1A) are added, the waviness increases slightly compared to IM7/LY556. Sample with nonfunctionalized CNT (IM7/1AP) shows a reduction of $73 \%$. In the RMS parameter, the difference between each type of CNT is more evident than for Wq. For the RMS, it is concluded that only the chemical dispersion presents significant differences when compared with the samples without any dispersion step. For waviness, it is observed that the mechanical dispersion influences the value of Wq. IM7/1T has a Wq value of $1726 \mathrm{~nm}$, and it is improved to $1504 \mathrm{~nm}$ when the dispersing agent is added (IM7/1TD). The same behavior is verified for IM7/1AP, where Wq of IM7/1AP is $948 \mathrm{~nm}$, and for the same sample dispersed in three-roll miller machine (IM7/1AP-3R) Wq is $884 \mathrm{~nm}$. For the sample with the highest CNT concentration, Wq parameter presents the value of $696 \mathrm{~nm}$ and, unlike what is expected, it is one of the best results. Similar to RMS, once again the best results correspond to the sample with thicker resin layer (IM7/1AP(4)-3R).

The difference between RMS and Wq can indicate that the dispersion and the concentration of CNT mainly influence the large irregularities, since only significant differences in waviness are visualized. This conclusion is in agreement with what discussed previously for RMS, where it is mentioned that the dispersion in the three-roll mill machine disperses the large agglomerates, responsible for large irregularities, being more effective in reduction of waviness.

Relatively to $\mathrm{W}_{\mathrm{zDIN}}$ results, when a LY556 layer is added to IM7, this parameter has been drastically reduced to $1520 \mathrm{~nm}$ (57\%) and further reduced when CNT are added. Functionalized CNT do not present significant changes between them, even when the dispersing agent is added to IM7/1T. The nonfunctionalized CNT showed a $\mathrm{W}_{z \mathrm{DIN}}$ of 
TABLE 4: 2D parameters of waviness measurement of materials prepared ${ }^{\mathrm{a}}$.

\begin{tabular}{|c|c|c|c|c|c|c|c|c|}
\hline \multirow{2}{*}{$\begin{array}{l}\text { Composite } \\
\text { designation }\end{array}$} & \multicolumn{2}{|c|}{$\mathrm{W}_{\mathrm{q}}$} & \multicolumn{2}{|c|}{$\mathrm{W}_{\mathrm{zDIN}}$} & \multicolumn{2}{|c|}{$\mathrm{W}_{\max }$} & \multicolumn{2}{|c|}{$\mathrm{W}_{\max }-\mathrm{W}_{\mathrm{zDIN}}$} \\
\hline & $\begin{array}{l}\text { Measurement } \\
(\mathrm{nm})\end{array}$ & $\begin{array}{l}\text { Reduction } \\
(\%)\end{array}$ & $\begin{array}{l}\text { Measurement } \\
(\mathrm{nm})\end{array}$ & $\begin{array}{c}\text { Reduction } \\
(\%)\end{array}$ & $\begin{array}{l}\text { Measurement } \\
(\mathrm{nm})\end{array}$ & $\begin{array}{c}\text { Reduction } \\
(\%)\end{array}$ & $\begin{array}{l}\text { Measurement } \\
(\mathrm{nm})\end{array}$ & $\begin{array}{c}\text { Reduction } \\
\text { (\%) }\end{array}$ \\
\hline IM7 & 3488 & $\mathrm{X}$ & 3530 & $\mathrm{X}$ & 5848 & $\mathrm{X}$ & 2318 & $\mathrm{X}$ \\
\hline IM7/LY556 & 1523 & 56 & 1520 & 57 & 2460 & 58 & 940 & $59 \%$ \\
\hline IM7/1T & 1726 & 51 & 1106 & 69 & 2209 & 62 & 1103 & $52 \%$ \\
\hline IM7/1A & 1921 & 45 & 1501 & 57 & 2240 & 62 & 739 & $68 \%$ \\
\hline IM7/1TD & 1504 & 57 & 913 & 74 & 1704 & 71 & 791 & $66 \%$ \\
\hline IM7/1AP & 948 & 73 & 555 & 84 & 962 & 84 & 407 & $82 \%$ \\
\hline $\begin{array}{l}\mathrm{IM} 7 / 1 \mathrm{AP}(4)- \\
3 \mathrm{R}\end{array}$ & 469 & 87 & 416 & 88 & 669 & 89 & 253 & $89 \%$ \\
\hline IM7/1AP-3R & 884 & 75 & 708 & 80 & 1576 & 73 & 868 & $63 \%$ \\
\hline IM7/2AP-3R & 696 & 80 & 682 & 81 & 1145 & 80 & 463 & $80 \%$ \\
\hline
\end{tabular}

${ }^{a}$ Results represent the average of values for both directions studied. The percentage of reduction is relative to IM7 composite.

$555 \mathrm{~nm}$, suggesting an improvement of the surface, wherein differences between the higher and lower peak of the profile are smaller. The dispersion of CNT in the three-roll machine and the increase of CNT concentration slightly increase the $\mathrm{W}_{\mathrm{zDIN}}$ value. IM7/1AP(4)-3R presents the lowest value of $\mathrm{W}_{\mathrm{zDIN}}$ and, consequently, more homogeneous surface.

As for roughness parameters, $\mathrm{W}_{\mathrm{zDIN}}$ and $\mathrm{W}_{\max }$ complement each other. The difference between $\mathrm{W}_{\max }$ and $\mathrm{W}_{\mathrm{zDIN}}$ for composite IM7 is $2318 \mathrm{~nm}$, suggesting a heterogeneous surface. The addition of the top resin layer decreases this value to $940 \mathrm{~nm}$ (59\%). As for roughness, when thermally functionalized CNT are added as top layer, the surface quality decreases. Other types of functionalizations (IM7/1A and IM7/1TD) make the surface more homogeneous with smaller differences between the two parameters and a reduction from $66 \%$ to $68 \%$ relatively to IM7. Samples prepared with "as produced" CNT presented a smaller difference between $\mathrm{W}_{\mathrm{zDIN}}$ and $\mathrm{W}_{\text {max }}$, with the exception of the sample dispersed in a three-roll miller machine (IM7/1AP-3R).

3.3. Effect of Surface Microstructure. SEM analysis of the samples was performed to evaluate the surface microstructure. The images obtained are shown in Figure 4.

The sample without a top layer seems to be dry with an irregular fracture. This can indicate poor adhesion between prepreg layers. This effect is minimized by adding the top layer of the resin and further by adding CNT. There are no significant differences between different functionalizations. However, for sample with CNT thermally oxidized and chemically dispersed (IM7/1TD), fracture seems to be more regular and top layers less dry, suggesting that dispersion increases the adhesion between different layers. The "as produced" CNT-based samples present a more regular fracture, suggesting that this CNT type improves the adhesion between the prepreg layers. As expected, the sample with a thicker resin layer is $\operatorname{IM} 7 / 1 \mathrm{AP}(4)-3 \mathrm{R}$. For the remaining conditions, the thickness of the resin layer is expected to be similar. However, SEM images reveal that samples prepared with nonfunctionalized CNT (IM7/1AP, IM7/1AP-3R and IM7/2AP3R) presented a CNT layer thicker than other samples with the same amount of resin. As mentioned in the roughness parameters analysis, the main difference explaining these different results is the functionalization of the CNT and its interaction with matrix. CNT functionalization improves its affinity with the matrix [30] and, in this specific case, promotes the migration to the prepregs. In the case of samples prepared with no functionalized CNT, the CNT have a lower affinity for the matrix, avoiding resin flow to the prepreg layers during the curing cycle.

SEM images also reinforce $\mathrm{Wq}$ values. Sample with pure resin (IM7/LY556) and with acid and thermally oxidized CNT (IM7/1A and IM7/1T) presented a thinner top layer, covering the surface waviness, presenting higher values of Wq. When a dispersant is added to the thermally oxidized CNT (IM7/1TD), it is seen that the top layer covers the waviness, slightly decreasing the value of Wq. For samples prepared with nonfunctionalized CNT, it is visualized that the top layer homogeneously covers the waviness, presenting the lowest values of Wq. As indicated before, the sample with a thicker CNT layer (IM7/1AP(4)-3R) has the smallest Wq value, with the fiber coverage by the resin being clearly visible in Figure 4.

Figure 5 presents three surface micrographs with higher magnification of IM7 and samples with the highest and the lowest roughness values.

IM7 presents a considerable amount of dry regions where the fibers are exposed. It is also observed that this sample has some waviness on the surface, which follows the texture expected by the prepreg structure (print-through effect). For IM7/1T and IM7/1AP(4)-3R it is possible to observe that the waviness of the fiber is covered by the CNT layer, confirming the good adhesion between two layers and making the surface more smooth and regular.

Surface micrographs were also obtained by SEM, to more directly compare the surface microstructure with the roughness results (Figure 6).

In the first image, it is visible that the IM7 has a very irregular surface, where fiber print-through of the ribs of the fiber is clearly identified. This effect is minimized when 
IM7

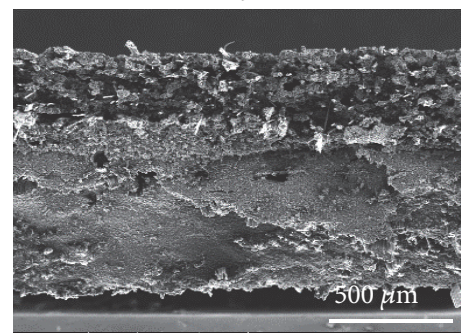

$\mathrm{IM} 7 / 1 \mathrm{~A}$

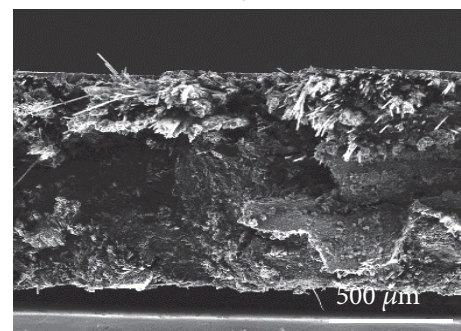

IM7/1AP-3R

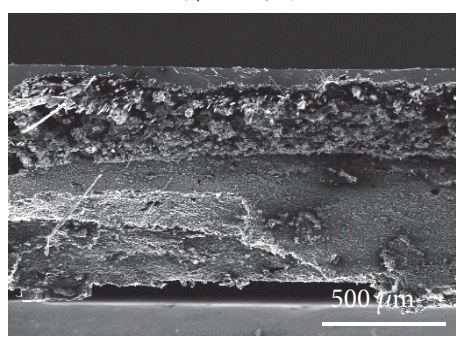

IM7/LY556

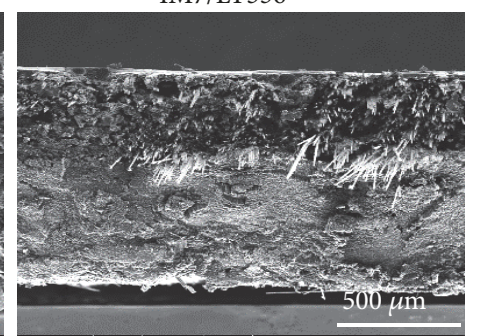

IM7/1T

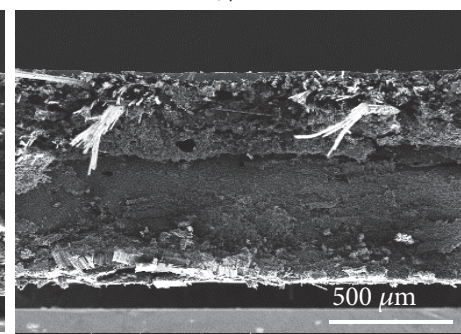

IM7/1AP(4)-3R

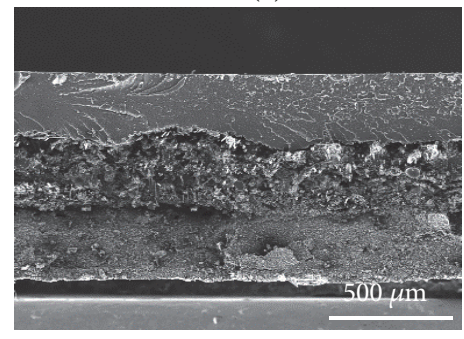

IM7/1AP

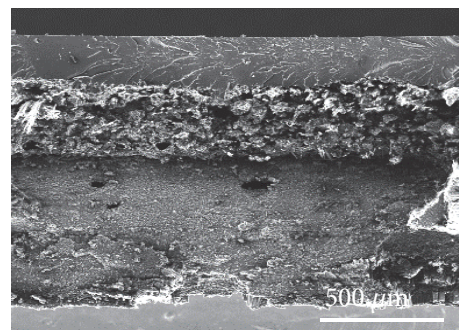

IM7/1TD

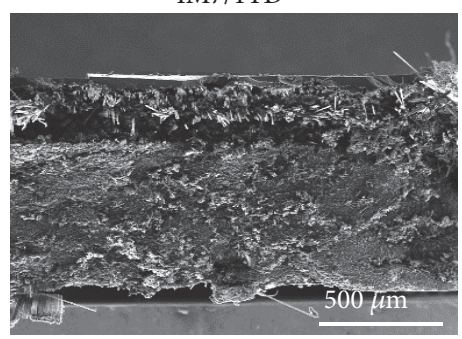

IM7/2AP-3R

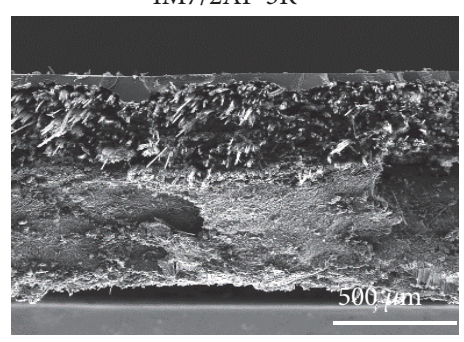

FIGURE 4: Cross-sectional images of prepared composites with magnification x140.
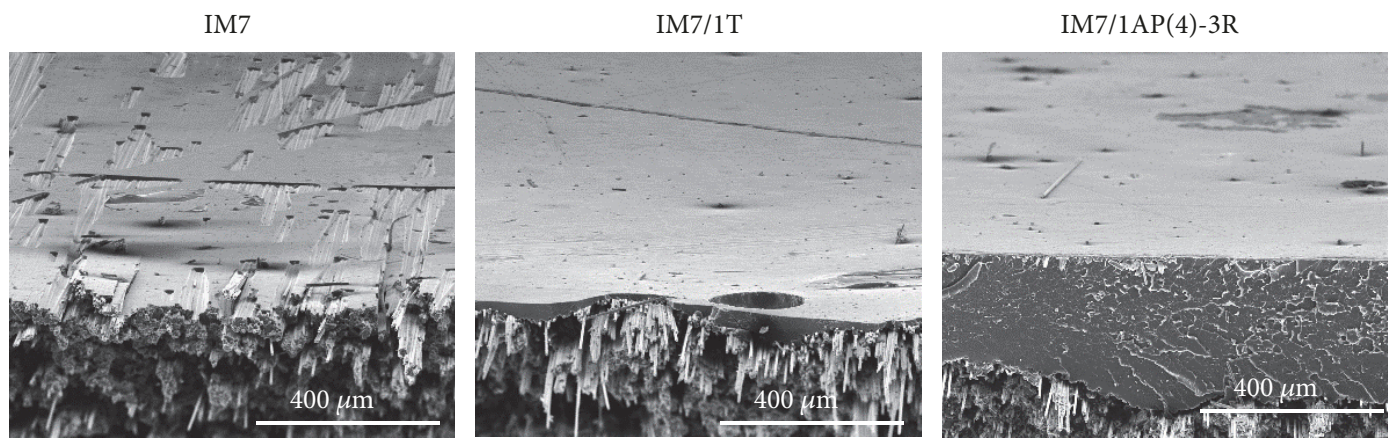

FIGURE 5: SEM images of IM7, IM7/1T, and IM7/1AP(4)-3R composites with magnification x250.

the top layer is added regardless of the CNT type. In the samples IM7/LY556, IM7/1A, and IM7/1T also some fiber print-through is visible, but smaller than IM7. In image relative to the sample with coating of thermally oxidized CNT (IM7/1T), there are very large ribs on the surface, being thinner for sample with pure resin (IM7/LY556) and less evident for the sample with acid oxidized CNT (IM7/1A). This visual inspection is in agreement with RMS results, where IM7/1T presents the highest RMS value $(875 \mathrm{~nm})$ for samples with resin top layer, followed by IM7/LY556 and IM7/1A. By this result, it can be concluded that samples with higher RMS value have a higher fiber print-through effect. Samples with thermally oxidized CNT with dispersing agent (IM7/1TD) and 2 wt.\% nonfunctionalized CNT (IM7/2AP-3R) presented a granular surface texture, where the fiber print-through is not perceptible. This fact explains the very similar values of RMS between both samples, $254 \mathrm{~nm}$ and $230 \mathrm{~nm}$, respectively. The results are in agreement with those previously discussed: the addition of a dispersing agent decreases the roughness of the samples prepared with functionalized CNT, while increasing the "as produced" CNT to 2 wt. $\%$ increases the surface roughness.

The remaining samples prepared with nonfunctionalized CNT have a regular and smooth surface. As expected, the sample with thicker resin top layer (IM7/1AP(4)-3R) has the smoothest surface, with this result being reinforced by a RMS 


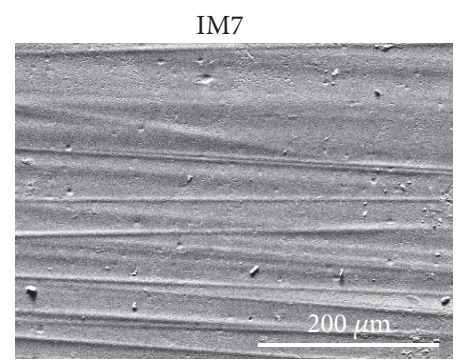

IM7/1A

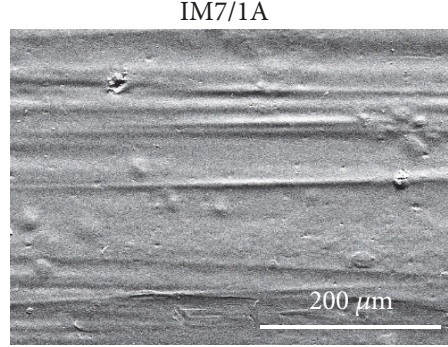

IM7/1AP-3R

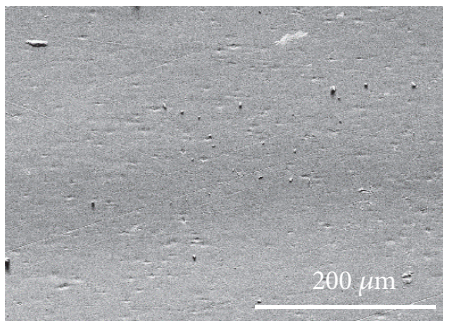

IM7/LY556

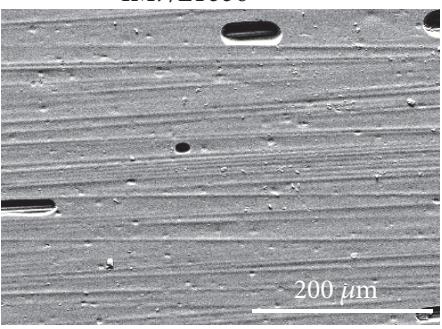

$\mathrm{IM} 7 / 1 \mathrm{~T}$

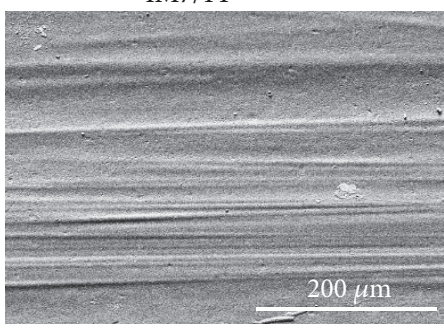

IM7/1AP(4)-3R

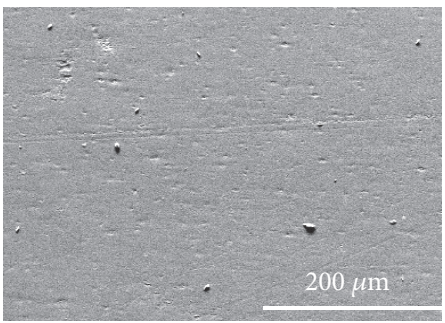

IM7/1AP

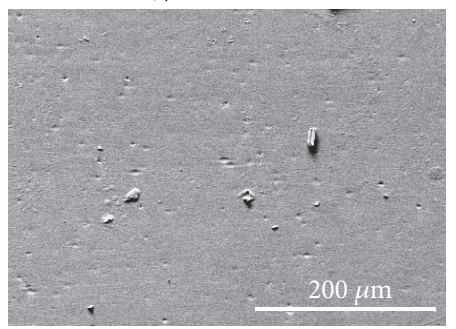

IM7/1TD

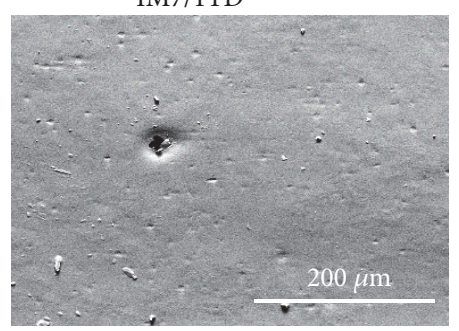

IM7/2AP-3R

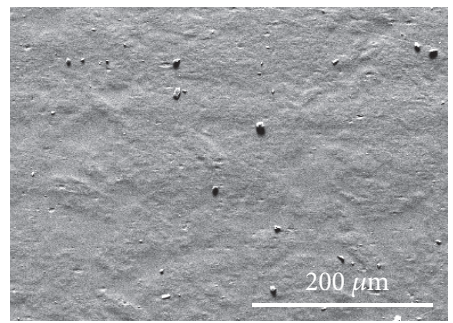

FIGURE 6: Surface images of prepared composites with magnification of x500, in BSE mode.

value of $100 \mathrm{~nm}$. However, in the samples with a thin layer of nonfunctionalized CNT (IM7/1AP and IM7/1AP-3R), it can be seen that the surface is not very different from the thicker resin layer sample, suggesting that only a small layer of resin $(125 \mu \mathrm{m})$ is sufficient to considerably reduce the fiber printthough effect.

\section{Conclusions}

Fiber print-through is a limitation of the use of CFRP composites in applications requiring surface optical accuracy. To mitigate fiber print-through, a resin layer modified with carbon nanotubes is applied to the top layer of CFRP. The effect of the top layer thickness and CNT functionalization, dispersion, and concentration on surface parameters was evaluated.

The interferometry analysis was performed to access the composite surface roughness and waviness. This analysis was complemented by SEM results of composite surface.

With the addition of the resin layer, surface roughness decreased by $65-96 \%$, with nonfunctionalized CNT exhibiting the greatest reductions. This fact can be explained by the lower affinity of the CNT with the matrix, which does not allow the migration of the CNT-resin through the prepregs. This hypothesis is confirmed by SEM analysis, where a thicker top layer is observed for samples prepared with no functionalized nanotubes.
The influence of different methods of dispersion (chemical and mechanical) on roughness and waviness has also been studied. It was verified that the chemical dispersion (IM7/1TD) significantly improved RMS, while mechanical dispersion using a three-roll mill machine did not show significant improvement in RMS. On the other hand, it was also concluded that the mechanical dispersion and the higher concentration of CNT mainly influence the large irregularities, since only significant differences are visualized in waviness.

The sample with thicker resin layer (IM7/1AP(4)-3R) has the best results, but the compromise between the thickness of the CNT layer and the final composite weight increase is necessary. For this, it is important to note that only with a thin layer of $125 \mu \mathrm{m}$, RMS decreases considerably (IM7/1AP and IM7/1AP-3R).

In surface images of SEM, it is observed that the addition of the resin layer, with or without CNT, attenuates the fiber print-through and the surface presents a more regular texture. In particular, the addition of CNT without functionalization makes surface more smooth and flat, presenting the less granular texture.

The application of a matrix doped with CNT to improvement composite properties (mechanical, thermal, and electrical) is well known, and in this study, a new application in surface for optical applications was presented. The top surface layer of resin layer with CNT on the top of the CFRP 
was effective in improving surface parameters (waviness and roughness), greatly reducing the fiber print-through. With a view on an application in optical mirrors, more studies are needed.

\section{Data Availability}

The data used to support the findings of this study are available from the corresponding author upon request.

\section{Conflicts of Interest}

The authors declare that there are no conflicts of interest regarding the publication of this paper.

\section{Acknowledgments}

The authors would like to acknowledge funding from project NORTE-01-0145-FEDER-000022 SciTech Science and Technology for Competitive and Sustainable Industries cofinanced by Programa Operacional Regional do Norte (NORTE2020), through Fundo Europeu de Desenvolvimento Regional (FEDER).

\section{References}

[1] J. Cheng, The Principles of Astronomical Telescope Design, Springer, New York, NY, USA, 2009.

[2] Y. Arao, J. Koyanagi, S. Utsunomiya, S. Takeda, and H. Kawada, "Time-dependent deformation of surface geometry on light weight and thermally stable CFRP mirror in humid environment," in Proceedings of the SPIE 7739, Modern Technologies in Space- and Ground-based Telescopes and Instrumentation, E. Atad-Ettedgui and D. Lemke, Eds., vol. 7739, Washington, USA, 2010.

[3] P. C. Chen, T. T. Saha, A. M. Smith, and R. Romeo, "Progress in very lightweight optics using graphite fiber composite materials," Optical Engineering, vol. 37, no. 2, p. 666, 1998.

[4] R. C. Romeo and R. N. Martin, "Progress in 1m-class lightweight CFRP composite mirrors for the ULTRA Telescope," in Proceedings of the SPIE 6273, Optomechanical Technologies for Astronomy, E. Atad-Ettedgui, J. Antebi, and D. Lemke, Eds., vol. 6273, Washington, USA, 2006.

[5] S. Utsonomiya, T. Kamiya, and R. Shimizu, "Improvement of CFRP composite mirrorsurface using replica method," in Proceedings of the 18th International Conference on Composite Materials, Jeju Island, Korea, August 2011.

[6] C. Wilcox, B. Fernandez, J. Bagnasco, T. Martinez, R. Romeo, and B. Agrawal, "The meter-class carbon fiber reinforced polymer mirror and segmented mirror telescope at the Naval Postgraduate School," in Proceedings of the SPIE 9354, FreeSpace Laser Communication and Atmospheric Propagation, $\mathrm{H}$. Hemmati and D. M. Boroson, Eds., p. 8, Washington, USA, 2015.

[7] S. Utsunomiya, T. Kamiya, and R. Shimizu, "Development of CFRP mirrors for low-temperature application of satellite telescopes," in Proceedings of the Modern Technologies in Space- and Ground-based Telescopes and Instrumentation II, R. Navarro, C. R. Cunningham, and E. Prieto, Eds., Proceedings of SPIE, p. 84502R, Amsterdam, Netherlands, 2012.
[8] J. Koyanagi, Y. Arao, H. Terada et al., "Development of space telescope mirror made by light and thermally stable CFRP," in Proceedings of the Fourth International Conference on Experimental Mechanics, C. Quan, K. Qian, A. K. Asundi, and F. S. Chau, Eds., Proceedings of SPIE, Singapore, 2010.

[9] J. J. Massarello, J. S. Welsh, J. D. Hochhakter et al., "Fiber printthrough mitigation technique for composite mirror replication," Optical Engineering, vol. 45, Article ID 123401, 2006.

[10] T. Kamiya, S. Utsunomiya, K. Komatsu, and R. Shimizu, "Improvement of the CFRP composite mirror surface using a replica method," in Proceedings of the 18th International Conference on Composite Materials, Jeju Island, Korea, August, 2011.

[11] O. Breuer and U. Sundararaj, "Big returns from small fibers: A review of polymer/carbon nanotube composites," Polymer Composites, vol. 25, p. 630, 2004.

[12] J. N. Coleman, U. Khan, and Y. K. Gun'ko, "Mechanical Reinforcement of Polymers Using Carbon Nanotubes," Advanced Materials, vol. 18, p. 689, 2006.

[13] S. K. Pillai and S. S. Ray, "Epoxy-based Carbon Nanotubes Reinforced Composites," in Advances in Nanocomposites Synthesis, Characterization and Industrial Applications, D. B. Reddy, Ed., 2011.

[14] R. Andrews and M. C. Weisenberger, "Carbon nanotube polymer composites," Current Opinion in Solid State and Materials Science, vol. 8, p. 31, 2004.

[15] O. Gohardani, M. C. Elola, and C. Elizetxea, "Potential and prospective implementation of carbon nanotubes on next generation aircraft and space vehicles: A review of current and expected applications in aerospace sciences," Progress in Aerospace Sciences, vol. 70, pp. 42-68, 2014.

[16] K. K. Sairajan, G. S. Aglietti, and K. M. Mani, "A review of multifunctional structure technology for aerospace applications," Acta Astronautica, vol. 120, p. 30, 2016.

[17] P. C. Chen and D. Rabin, "Carbon nanotube optical mirrors," Journal of Astronomical Telescopes, Instruments, and Systems, vol. 1, 2014.

[18] H. G. Kia, "Print through reduction in long fiber reinforced composites by addition of carbon nanotubes," U.S. Patent 8.486.321 B2 (Assignee: GM Global Technology Operations LLC, Detroit, MI (US)), 2013.

[19] K. Mizuno, J. Ishii, H. Kishida et al., "A black body absorber from vertically aligned single-walled carbon nanotubes," Proceedings of the National Academy of Sciences of the United States of America, vol. 106, p. 15.

[20] J. Wang, G. Liang, H. Yan, and S. He, "Needleless electrospinning of nanofibers with a conical wire coil," Polymer Engineering \& Science, vol. 49, p. 4, 2009.

[21] Y. Chou, C. Juan, L. Yen et al., "The study of multiwall carbon nanotubes light reflectivity," in Proceedings of the IEEE 4th International Nanoelectronics Conference, Taiwan, China, June 2011.

[22] H. Shi, J. G. Ok, H. W. Baac, and L. J. Guo, "Low density carbon nanotube forest as an index-matched and near perfect absorption coating," Applied Physics Letters, vol. 99, no. 21, p. 211103, 2011.

[23] P.-C. Ma, N. A. Siddiqui, G. Marom, and J.-K. Kim, "Dispersion and functionalization of carbon nanotubes for polymer-based nanocomposites: A review," Composites Part A: Applied Science and Manufacturing, vol. 41, p. 1345, 2010. 
[24] P. G. Benardos and G.-C. Vosniakos, "Predicting surface roughness in machining: a review," International Journal of Machine Tools and Manufacture, vol. 43, no. 8, pp. 833-844, 2003.

[25] E. S. Gadelmawla, M. M. Koura, T. M. A. Maksoud, I. M. Elewa, and H. H. Soliman, "Roughness parameters," Journal of Materials Processing Technology, vol. 123, pp. 133-1445, 2002.

[26] L. Vaisman, H. D. Wagner, and G. Marom, "The role of surfactants in dispersion of carbon nanotubes," Advances in Colloid and Interface Science, vol. 37, pp. 128-130, 2006.

[27] R. Rastogi, R. Kaushal, S. K. Tripathi, A. L. Sharma, I. Kaur, and L. M. Bharadwaj, "Comparative study of carbon nanotube dispersion using surfactants," Journal of Colloid and Interface Science, vol. 328, no. 2, pp. 421-428, 2008.

[28] M. R. Loss, L. A. F. Coelho, S. H. Pezzin, and S. C. Amico, "Effect of carbon nanotubes addition on the mechanical and thermal properties of epoxy matrices," Materials Research, vol. 11, p. 347, 2008.

[29] S. W. Kim, T. Kim, Y. S. Kim et al., "Surface modifications for the effective dispersion of carbon nanotubes in solvents and polymers," Carbon, vol. 50, no. 1, pp. 3-33, 2012.

[30] G. S. Nanda, R. Sravendra, W. C. Jae, L. Lin, and H. C. Siew, "Polymer nanocomposites based on functionalized carbon nanotubes," Progress in Polymer Science, vol. 35, no. 7, pp. 837867,2010 


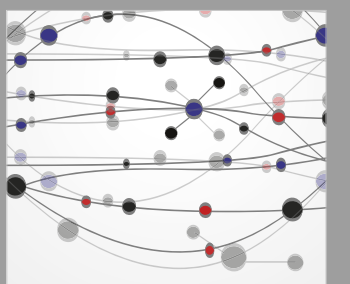

The Scientific World Journal
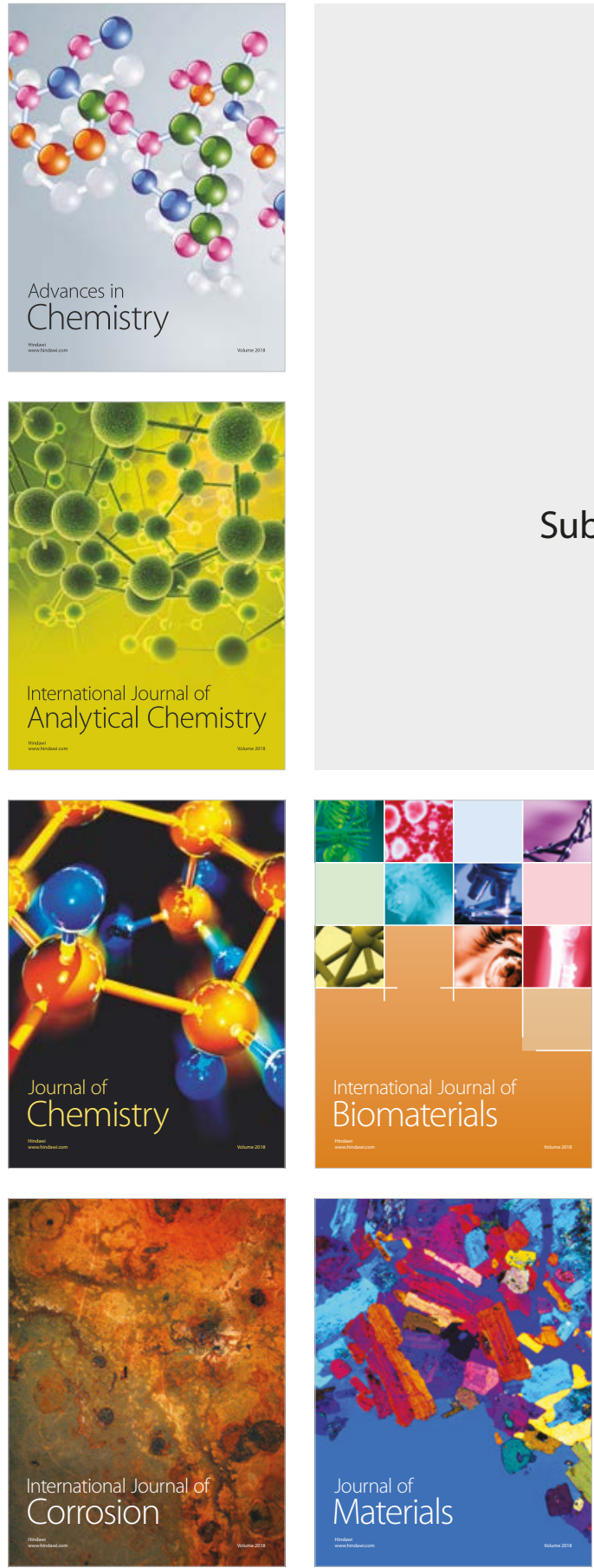

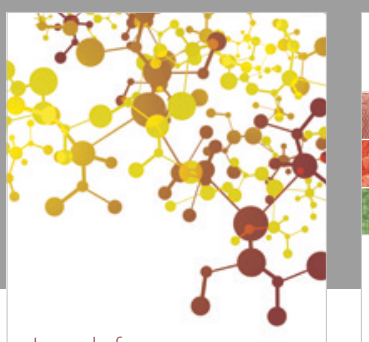

Journal of

Applied Chemistry
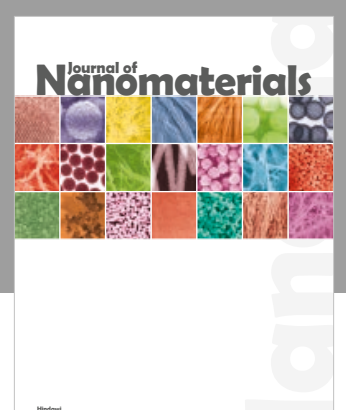

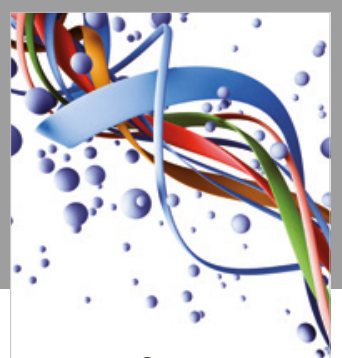

Scientifica

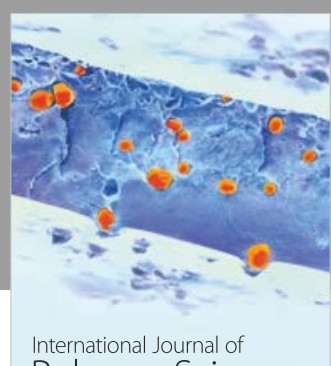

Polymer Science

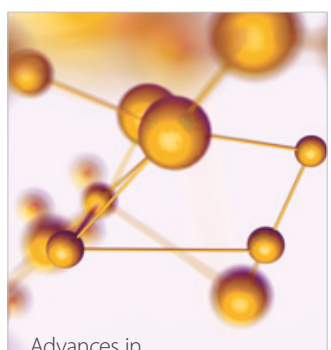

Physical Chemistry
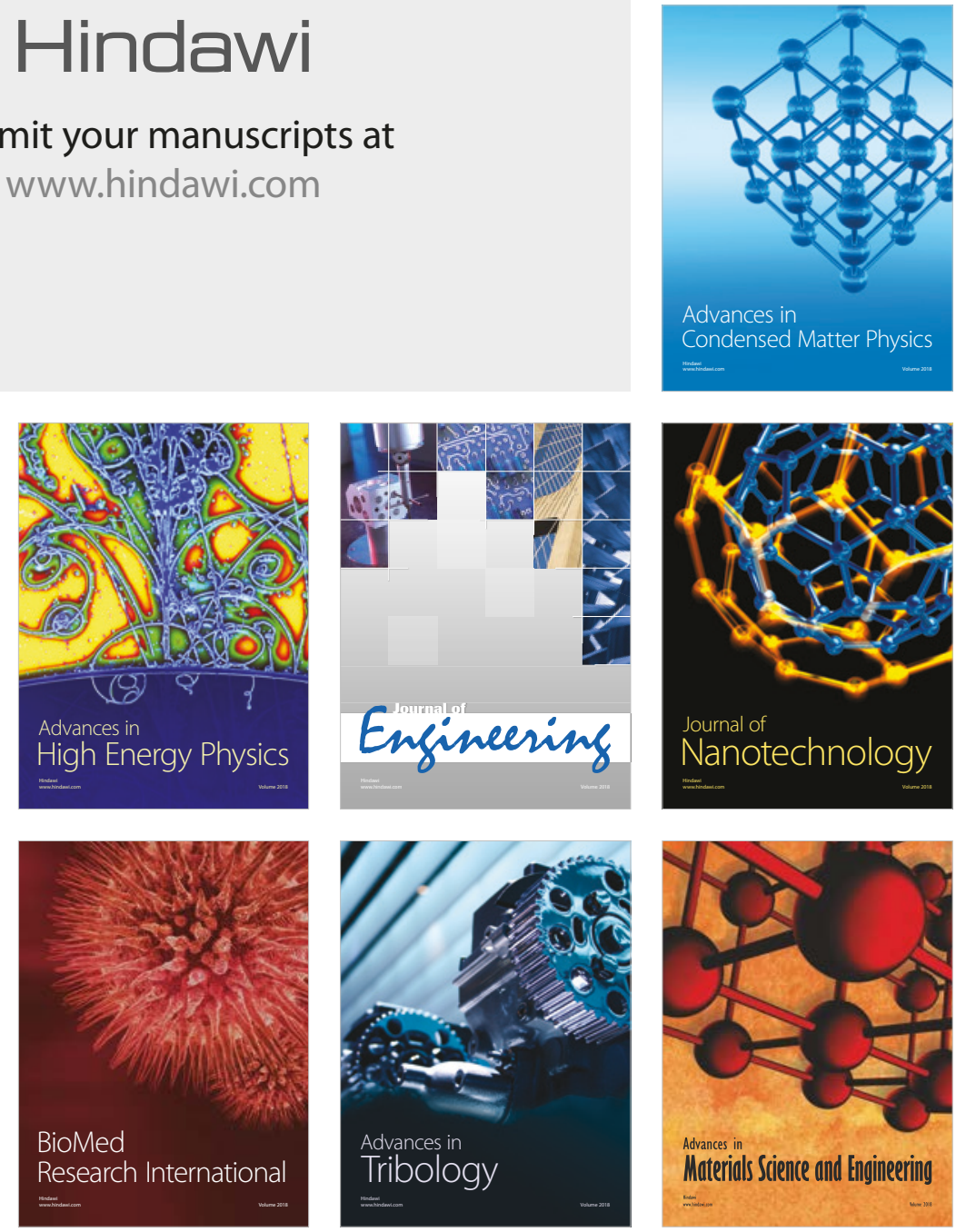